from a tarsometatarsal (Lisfranc) dislocation is important (Faciszewski, Burks and Manaster 1990).

Our patient presented at three weeks and conservative treatment enabled her to return to athletics without symptoms seven months after the injury. O'Donoghue (1976) recommended complete reduction and internal fixation followed by non-weight-bearing for four weeks and an arch support for one year.

No benefits in any form have been received or will be received from a commercial party related directly or indirectly to the subject of this article.

\section{REFERENCES}

Cain PR, Seligson D. Lisfranc's fracture-dislocation with intercuneiform dislocation: presentation of two cases and a plan for treatment. Foot \& Ankle 1981; 2:156-60.

Denton JR. A complex Lisfranc fracture-dislocation. J Trauma 1980; 20:526-9.
Faciszewski T, Burks RT, Manaster BJ. Subtle injuries of Lisfranc joint. J Bone Joint Surg [Am] 1990; 72-A:1519-22.

Lewin P. The foot and ankle. Philadelphia: Lea and Febiger, 1959: 110-3.

Morton DJ. Hypermobility of first metatarsal bone: the interlinking factor between metatarsalgia and longitudinal arch strains. $J$ Bone Joint Surg 1928: 10:187-96.

O'Donoghue DH. Treatment of injuries to athletes. 3rd ed. Philadelphia : WB Saunders, 1976:760-1.

Schiller MG, Ray RD. Isolated dislocation of the medial cuneiform bone: a rare injury of the tarsus. J Bone Joint Surg [Am] 1970; 52A :1632-6.

Smith JS Jr, Kanat IO, Pupp G, Pupp J. Fracture and dislocation of the middle cuneiform: a case report. J Am Podiatr Med Assoc 1984; 74:406-10.

Wargon CA, Goldman FD. Lisfranc fracture dislocation: a variation. J Am Podiatr Med Assoc 1986; $76: 466-8$.

Wiley JJ. The mechanism of tarso-metatarsal joint injuries. $J$ Bone Joint Surg [Br] $1971: 53-\mathrm{B}: 474-82$.

\title{
REGIONAL PROPHYLACTIC ANTIBIOTIC IN KNEE ARTHROPLASTY
}

\author{
C. HODDINOTT, A. M. LOVERING
}

During arthroplasty, antibiotic prophylaxis usually involves the systemic administration of a second-generation cephalosporin (Hill et al 1981). We have used regional intravenous administration of cefuroxime to cover knee arthroplasty, finding that this achieved and maintained much higher bone and fat concentrations than the conventional systemic method (Hoddinott et al 1990). Our findings have been confirmed using cephamandole (Field et al 1992).

The greatest risk of infection of a surgical wound is in the first 24 hours; antibiotic cover should continue for this period (Bannister 1986). We have measured the concentration of cefuroxime in the drainage from knee arthroplasties to provide a pharmacokinetic profile of regionally administered cefuroxime in haematoma fluid during the 24 hours after operation.

Patients and methods. Five patients who did not receive antibiotics in the 72 hours before operation gave their informed consent for the study, which was approved by the local ethics committee. After exsanguination by elevation a thigh tourniquet was inflated. A dose of

C. Hoddinott, FRCS, FRCS Ed, Senior Orthopaedic Registrar Department of Orthopaedic Surgery, Royal Gwent Hospital, Cardiff Road. Newport NP9 2UB, UK.

A. M. Lovering, PhD, Principal Clinical Scientist

Department of Medical Microbiology, Southmead Hospital, Westburyon-Trym, Bristol BS10 5NB, UK.

Correspondence to $\mathrm{MrC}$. Hoddinott.

(C) 1993 British Editorial Society of Bone and Joint Surgery

$0301-620 X / 93 / 1$ R $52 \$ 2.00$

J Bone Joint Surg [Br] 1993; 75-B: 157-8.

Received 27 September 1991; Accepted 22 November 1991
$750 \mathrm{mg}$ of cefuroxime in $100 \mathrm{ml}$ of water was then injected over a two-minute period into a foot vein. After knee arthroplasty a single suction drain was used, and samples of the drainage fluid were taken every four hours for 24 hours. They were centrifuged at $2000 \mathrm{~g}$ for five minutes, the supernatant removed, and stored at $-70^{\circ} \mathrm{C}$. Assay for cefuroxime was by high-performance liquid chromatography (Hoddinott et al 1990).

Results. The haematoma concentrations of cefuroxime are shown in Table I and in Figure 1. The levels ranged

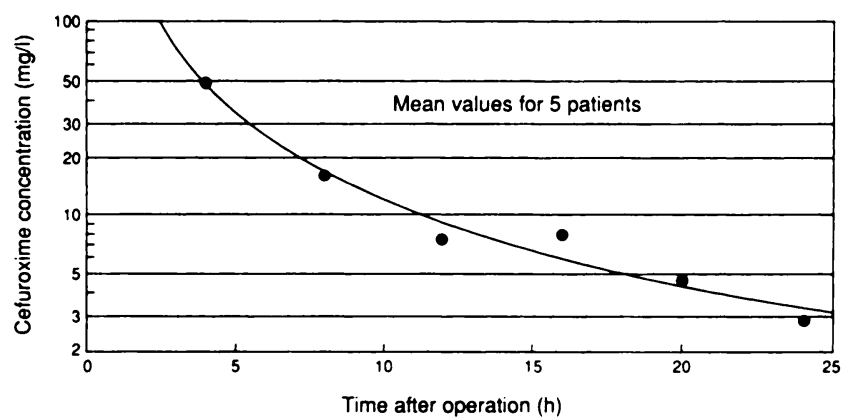

Fig. 1

from $95.8 \mathrm{mg} / \mathrm{l}$ at four hours to an undetectable level $(<0.3 \mathrm{mg} / \mathrm{l})$ at 24 hours in one patient. The mean levels were $48.7 \mathrm{mg} / \mathrm{l}$ at four hours and $2.7 \mathrm{mg} / \mathrm{l}$ at 24 hours. All levels, except the single very low one, were inhibitory for the common pathogens, such as Staphylococcus aureus and Staphylococcus epidermidis. With the one exception, effective levels were maintained for 24 hours after the operation. There were no side-effects from this route of 
Table I. Cefuroxime concentrations $(\mathrm{mg} / \mathrm{l})$ in drainage fluid after a single regional intravenous dose

\begin{tabular}{|c|c|c|c|c|c|c|}
\hline \multirow{2}{*}{$\begin{array}{l}\text { Time after } \\
\text { operation } \\
\text { (hours) }\end{array}$} & \multicolumn{5}{|c|}{ Patient } & \multirow[b]{2}{*}{ Mean } \\
\hline & 1 & 2 & 3 & 4 & 5 & \\
\hline 4 & 28.2 & 16.4 & 28.3 & 95.8 & 75.1 & 48.7 \\
\hline 8 & 18.2 & 4.5 & 13.3 & 30.3 & 13.2 & 15.9 \\
\hline 12 & 12.4 & 4.6 & 6.0 & 13.5 & * & 7.3 \\
\hline 16 & 9.0 & 3.5 & 6.2 & 12.3 & 7.8 & 7.7 \\
\hline 20 & 5.4 & 1.8 & 4.4 & 5.4 & 5.0 & 4.4 \\
\hline 24 & 3.6 & 2.1 & 0.0 & 4.8 & 2.8 & 2.7 \\
\hline
\end{tabular}

administration, and no cases of deep or superficial infection.

Discussion. We previously reported bone and fat levels some 12 times higher than those after systemic injection (Hoddinott et al 1990) and have now extended our sampling to provide a pharmacokinetic profile over the important 24 hours after operation (Fig. 1). The results indicate that the regional intravenous administration of a single $750 \mathrm{mg}$ dose of cefuroxime gave satisfactory haematoma levels for at least 20 hours in all our patients. The main reservoir for the antibiotic during this period is the bone, and bone levels are therefore probably higher than the haematoma level.

Our results suggest that a single dose of cefuroxime is adequate for postoperative prophylaxis, dispensing with the need for further systemic injections. Our numbers are too small to allow us to comment on infection rates, but it does seem logical to provide the maximum available antibiotic level at the operation site during the surgical procedure.

We recommend the use of the regional intravenous injection of a single dose of prophylactic antibiotic for knee arthroplasty performed under tourniquet.

We would like to thank Mr Bannen, Dr Yogesh and Mr Owen of Royal Gwent Hospital for their help in the collection and preparation of samples.

No benefits in any form have been received or will be received from a commercial party related directly or indirectly to the subject of this article.

\section{REFERENCES}

Bannister GC. Causes and prevention. II : bacteriology. Curr Orthop $1986 ; 1: 35-9$.

Field J, Webb J, Bannister GC, Lovering AM, Reeves DS. A comparison of three methods of antibiotic prophylaxis in knee arthroplasty. J Arthroplasty 1992; 7:17-9.

Hill C, Mazas F, Flamant R, Evrard J. Prophylactic cefazolin versus placebo in total hip replacement. Lancet 1981; I :795-7.

Hoddinott C, Lovering AM, Fernando HC, Dixon JH, Reeves DS. Determination of bone and fat concentrations following systemic cefamandole and regional cefuroxime administration in patients undergoing knee arthroplasty. J Antimicrob Chemother 1990; $26: 823-9$.

\section{AN EXTENDED TROCHANTERIC OSTEOTOMY FOR REVISION TOTAL HIP REPLACEMENT}

PAUl C. PETERS JR, William C. HEAD, ROGER H. EMERSON JR

There are now only rare indications for an osteotomy of the greater trochanter in primary total hip replacement, but some revisions necessitate the better access which it provides. The complications of trochanteric osteotomy include nonunion, fibrous union, chronic bursitis and broken wires. For revision cases, osteoporosis, osteolysis, and the lack of a suitable bed for the trochanter make reattachment more difficult. Various techniques of wire

P. C. Peters Jr, MD, Clinical Associate Professor of Orthopaedic Surgery

W. C. Head, MD, Clinical Associate Professor of Orthopaedic Surgery R. H. Emerson Jr, MD, Clinical Associate Professor of Orthopaedic Surgery.

University of Texas Health Science Centre

Reconstructive Orthopaedic Surgeons, P.A., 8230 Walnut Hill Lane. Suite 106, Dallas, Texas 75231-4170, USA

Correspondence to Dr P. C. Peters Jr.

(C) 1993 British Editorial Society of Bone and Joint Surgery

$0301-620 X / 93 / 1$ R60 $\$ 2.00$

J Bone Joint Surg [Br] 1993; 75-B: 158-9.

Received 24 December 1991; Accepted 19 February 1992 fixation and wire mesh reinforcement have been used, but the same complications continue to occur (Amstutz, Mai and Schmidt 1984; Kavanagh, Ilstrup and Fitzgerald 1985; Pellicci et al 1985; Schutzer and Harris 1988).

We describe an extended trochanteric osteotomy which allows for wider exposure and access, the adjustment of trochanteric position and abductor tension, and improved bone apposition.

Materials and methods. From 1988 to 1991, we performed 169 revision total hip arthroplasties using a trochanteric osteotomy. Of these, 21 had an extended trochanteric osteotomy. There were 13 men and eight women; ten had had more than one previous replacement and 15 had had a previous trochanteric osteotomy, all of which had united. All required increased exposure for major allografting and reconstruction of the acetabulum.

Surgical technique. For exposure, we use either a modified anterolateral extensile approach (Head et al 1987) or a trochanteric slide (Glassman, Engh and Bobyn 1987). The proximal femur is exposed and the trochanteric 